\title{
Metformin versus Insulin in Gestational Diabetes
}

\author{
ABDULLAH Kh. AHMED, M.D.; SAMIR Kh. GALAL, M.D. and ESAM A. ABDELAZIZ, M.Sc. \\ The Department of Obstetrics and Gynecology, Faculty of Medicine, Al-Azhar University
}

\begin{abstract}
Background: Metformin is a logical intervention assuming that the efficacy and safety of its use for pregnant patients are established.

Aim of Study: To assess the efficacy of metformin in controlling gestational diabetes compared to insulin.

Patients and Methods: This randomized controlled study was conducted on 214 patients with gestational diabetes recruited from the outpatient clinic of 6 th of October Central Hospital during the period from October 2019 to April 2021. After fulfilling criteria of inclusion and exclusion, patients were randomly assigned to either groups of treatment with either metformin or insulin. Serial of blood glucose level was assessed at enrolment and at follow-up visits. The outcomes were fetal and maternal outcomes.

Results: Fasting blood sugar and glycated hemoglobin were significantly lower $(p<0.001)$ in the metformin group compared to the insulin group. However, 2 hours postprandial blood sugar did not show significant differences $(p=0.105)$ between the two groups. Additionally, Metformin was beneficial in reducing maternal weight gain and neonatal birth weight. Furthermore, neonates in the metformin-treated group suffered fewer rates of neonatal hypoglycemia and NICU admission.
\end{abstract}

Conclusion: Metformin alone was as effective as insulin for controlling Gestational diabetes mellitus.

Key Words: Insulin - Metformin - Gestational diabetes mellitus.

\section{Introduction}

GESTATIONAL diabetes mellitus (GDM) is a major international health issue which has a growingprevalence in recent years. On account of the epidemic of obesity, the prevalence of overt diabetes in pregnancy and glucose intolerance in pregnancy (Gestational diabetes mellitus) has also risen. Globally, an estimated one in seven births are affected by GDM [1]

Correspondence to: Dr. Abdullah Kh. Ahmed, The Department of Obstetrics and Gynecology, Faculty of Medicine, Al-Azhar University
GDM is known as a condition in which a woman without diabetes develops glucose intolerance during pregnancy resulting in varying degrees of hyperglycemia [2]. A medical diagnosis of GDM changes a pregnancy from 'normal' to 'abnormal' and could potentially be associated with anxiety and depression for the reason that insufficiently controlled diabetes in pregnancy is closely linked with an increased incidence of adverse outcomes for both mother and infant [3] .

Most women are able to control their blood sugar with proper diet and exercise. If not, insulin injection is considered as the gold standard for GDM. However, several disadvantages of insulin treatment are recognized such as frequent injections, increased risk of hypoglycemia, and higher cost, which could reduce patient's compliance [4]. By contrast, oral agents (metformin and glyburide) present the advantages of easier management and lower cost, thus they become anattractive alternative to insulin with better acceptance, which enhances adherence to the treatment [5].

Metformin, an oral anti diabetic drug, has been used since 1960 in patients with Type-2 diabetes mellitus. It has been upgraded to a Category B drug as it is not associated with any fetal congenital anomalies [6]. It was initially used to reduce insulin resistance in females with the polycystic ovarian syndrome. It showed remarkable results with no side effects in pregnancyso it was considered a better alternative for the management of GDM. It can be a logical treatment for pregnant females as it produces the euglycemic state by improving insulin sensitivity, reducing hepatic gluconeogenesis, and increasing peripheral glucose uptake and Utilization [6]

The use of metformin in treatment of GDM has been endorsed by numerous professional and governmental organizations. Yet, guidelines emphasize the need for more information on the effects of 
Oral Hypoglycaemic Agents for GDM treatment $\left[{ }^{7}\right]$.

The objective of this study was to estimate the comparative effectiveness of metformin versus insulin in Egyptian women.

\section{Patients and Methods}

This was a randomized controlled clinical trial, including 214 pregnant women with gestational diabetes attending the outpatient clinic of 6 th of October Central Hospital from October 2019 to April 2021. They were divided into 2 equal groups:

Group A were treated by metformin. Metformin was started at a dose of 500mg and increased up to $2500 \mathrm{mg}$ in 3 divided doses as tolerated until glycemic control was achieved. Target blood sugar levels aimed at FBS $<95 \mathrm{mg} / \mathrm{dl}$ and postprandial levels $<120 \mathrm{mg} / \mathrm{dl}$. If blood glucose levels were higher than the cut off values 3 weeks after treatment or at anytime during treatment with maximum dose of metformin, the patient was shifted to insulin.

Group B were treated by insulin. They were given insulin human mixtard (30:70) subcutaneously. Total daily dose of premixed insulin at initiation was calculated for most patients as 0.7 IU/kg body weight and was increased as needed. Only $2 / 3$ rd of the above calculated dose was administered in the morning 30 minutes before breakfast and the remaining $1 / 3 \mathrm{rd}$ was given in the evening 30 minutes before supper.

The protocol was approved by the local research and Ethical Committee of the Department of Obstetrics and Gynecology of Al-Azhar, Faculty of Medicine. Every woman participated in the study was informed about the nature of study and gave a written consent.

\section{Inclusion criteria:}

1- Women with GDM between 20 week and 28 weeks of gestational age.

2- Patients aged (21-35) years.

3- Singleton pregnancy.

4- Failure to achieve glycemic control with exercise and diet during 1 week.

\section{Exclusion criteria:}

1- Pregnant with pre-existing diabetes (T1D or T2D).

2- Patients with fasting blood glucose levels $>125 \mathrm{mg} / \mathrm{dl}$ or $2 \mathrm{hPP}$ blood glucose level > $200 \mathrm{mg}$ $/ \mathrm{dl}$.
3- Women who have contraindications to metformin, e.g.liver cirrhosis, impaired renal function.

4- Patients with other medical disorders that may affect perinatal outcome (e.g., hypertension, SLE).

5- Pre-existing fetal anomalies identified by ultrasound prior to initiation of treatment.

All pregnant women attend to outpatient clinic were submitted to:

\section{Careful and detailed history:}

I- Personal history: Name, age, occupation, residence, special habits of medical importance and educational level.

II- Obstetric history:

- History of poor obstetric outcome (abortion, CFMF, IUFD, and neonatal death).

- Previous history of macrosomic baby.

- Previous history of GDM.

- Her first day of LMP for estimation of gestational age.

- History of previous Cesarean sections.

III- Past history: History of any medical disorders or any surgical history.

IV- Drug history and allergy.

V- Family history of diabetes in first degree relatives.

\section{Examination:}

- General examination (pulse, blood pressure, temperature, etc).

- Abdominal examination:

- Palpitation (fetal size, amount of liquor, fetal lie, fetal presentation).

- Inspection (size of uterus, scars, fetal movement).

- Vaginal examination (when indicated).

\section{Ultrasound examination to:}

1- Assess viability and fetal heart rate.

2- Exclude major abnormalities.

3- Assess fetal growth and Gestational age.

4- Assess the amount of liquor and evaluation of placenta.

Screening was done by A $50 \mathrm{~g}$ oral glucose challenge test (GCT) as an initial screening test, irrespective of the fasting status, a blood sugar level >_ $140 \mathrm{mg} / \mathrm{dl}(7.8 \mathrm{mmol} / 1)$ was considered a positive (GCT). Subsequently, these women had a $3 \mathrm{~h}$ oral glucose tolerance test (OGTT) after an overnight fasting (water was allowed). Diagnosis 
of GDM was made with at least two elevated plasma glucose levels:

- Fasting blood glucose level $\geq 95 \mathrm{mg} / \mathrm{dl}$ (5.33mmol /L).

- 1 hour blood glucose level $\geq 180 \mathrm{mg} / \mathrm{dl}(10 \mathrm{mmol}$ /L).

- 2 hour blood glucose level $\geq 155 \mathrm{mg} / \mathrm{dl}$ ( $8.6 \mathrm{mmol}$ /L).

- 3 hour blood glucose level $\geq 140 \mathrm{mg} / \mathrm{dl}$ ( $7.8 \mathrm{mmol}$ /L).

After confirmation of gestational diabetes mellitus, newly diagnosed clients were managed on diet and exercise according to the recommendationsof American Diabetes Association, [8]. They were advised to keep carbohydrate intake at $40 \%$ of total calorie intake with consumption of 30-32 $\mathrm{kcal} / \mathrm{kg}$ and also to select foods with low glycaemic index values. In addition, exercise was recommended to be three times a week for about $30 \mathrm{~min}$.

If glycemic targets were not achieved within 2 weeks, they were then recruited into the study and put on the treatment protocol.

Follow-up visits were arranged in the same antenatal clinic every 2 weeks till 36 weeks then weekly till delivery. At each antenatal visit, blood pressure and weight were measured, abdominal examination was done, and Ultrasound was done at first visit and then monthly. Fasting and $2 \mathrm{~h}$ postprandial blood glucose levels were done at each visit. HbAlc was done at the begining of study and at around 37 weeks of pregnancy. Method and time of delivery were decided around 38 weeks of pregnancy. Follow-up was continued till delivery to evaluate the pregnancy outcome. Neonatal assessment was assessed for 5-min APGAR score, blood glucose level, neonatal birth weight, respiratory distress syndrome (RDS), and the rate of neonatal intensive care unit (NICU) admissions.

\section{Statistical analysis:}

The program used was SPSS version 22. Quantitative data were analyzed using mean, standard deviation, and range. The frequency and percentage were used with qualitative data.

1- Independent-samples $t$-test of significance was used when comparing between two means.

2- Chi-square $\left(X^{2}\right)$ test of significance was used in order to compare proportions between two qualitative parameters.

3- The Confidence Intervals was set two $95 \%$ and the margin of error was set two $5 \%$.
4- Probability ( $p$-value): $p$-value $<0.05$ was considered significant.

\section{Results}

Of the 214 eligible women, 194 women completed the study (100 in the insulin group and 94 in the Metformin group). Patients had dropped out due to various reasons and were excluded from the study. Thirteen participants in the metformin group were excluded in the analysis ( 2 participants failed to follow-up, 1 participant withdrew her consent, 5 participants failed to reach glycemic control, and 5 participants couldn't tolerate GIT side effects). A total of 7 participants in the insulin group were also excluded, and the causes were failure to followup (4 participants), consent with drawals ( 2 participants), and discharge against medical advice (1 participants).

There was no significant difference between two groups regarding maternal age, weight, height, BMI, GA, parity and smoking at the start of study (Table 1).

Table (1): Comparison between the two groups regarding patient characteristic at the start of study.

\begin{tabular}{|c|c|c|c|}
\hline $\begin{array}{l}\text { Groups } \\
\text { Descriptive data }\end{array}$ & $\begin{array}{l}\text { Group A } \\
\text { Metformin } \\
\text { (No.=94) }\end{array}$ & $\begin{array}{l}\text { Group B } \\
\text { Insulin } \\
(\text { No.=100) }\end{array}$ & $\begin{array}{c}p- \\
\text { value }\end{array}$ \\
\hline $\begin{array}{l}\text { Maternal age (years): } \\
\text { Mean } \pm \mathrm{SD} \\
\text { Range }\end{array}$ & $\begin{array}{l}30.34 \pm 4.23 \\
22-35\end{array}$ & $\begin{array}{l}29.54 \pm 3.92 \\
21-35\end{array}$ & 0.174 \\
\hline $\begin{array}{l}\text { Weight }(\mathrm{kg}) \text { : } \\
\text { Mean } \pm \mathrm{SD} \\
\text { Range }\end{array}$ & $\begin{array}{l}78.51 \pm 13.18 \\
56-110\end{array}$ & $\begin{array}{l}80.57 \pm 14.92 \\
55-112\end{array}$ & 0.309 \\
\hline $\begin{array}{l}\text { Height }(\mathrm{cm}): \\
\text { Mean } \pm \mathrm{SD} \\
\text { Range }\end{array}$ & $\begin{array}{l}167.27 \pm 6.37 \\
157.5-190\end{array}$ & $\begin{array}{l}168.70 \pm 6.65 \\
157-192\end{array}$ & 0.128 \\
\hline $\begin{array}{l}B M I\left(\mathrm{~kg} / \mathrm{m}^{2}\right): \\
\quad \text { Mean } \pm \mathrm{SD} \\
\text { Range }\end{array}$ & $\begin{array}{c}28.01 \pm 4.12 \\
18.08-37.88\end{array}$ & $\begin{array}{l}28.28 \pm 4.85 \\
17.87-39.52\end{array}$ & 0.676 \\
\hline $\begin{array}{l}\text { Gestational age } \\
\text { (weeks): } \\
\text { Mean } \pm \mathrm{SD} \\
\text { Range }\end{array}$ & $\begin{array}{l}23.66 \pm 1.91 \\
20-28\end{array}$ & $\begin{array}{l}24.16 \pm 1.98 \\
21-28\end{array}$ & 0.075 \\
\hline $\begin{array}{l}\text { Parity: } \\
\text { Primigravida } \\
\text { Multigravida }\end{array}$ & $\begin{array}{l}28(29.8 \%) \\
66(70.2 \%)\end{array}$ & $\begin{array}{l}41(41.0 \%) \\
59(59.0 \%)\end{array}$ & 0.104 \\
\hline $\begin{array}{l}\text { Smoking: } \\
\text { Non-smoker } \\
\text { Smoker }\end{array}$ & $\begin{array}{l}85(90.4 \%) \\
9(9.0 \%)\end{array}$ & $\begin{array}{l}89(89.0 \%) \\
11(11.0 \%)\end{array}$ & 0.737 \\
\hline
\end{tabular}

There was no significant difference between both groups concerning the FBS in the beginning of the study. However, after 2 week of the treatment, the FBS levels were significantly lower in 
metformin and insulin groups. Additionally, the fasting blood sugar levels were significantly lower in the metformin group than in the insulin group (Table 2).

Table (2): Comparison between group A and group B according to fasting blood sugar (FBS).

\begin{tabular}{llll}
\hline \multicolumn{1}{c}{ Groups } & $\begin{array}{c}\text { Group A } \\
\text { Metformin } \\
\text { Variables }\end{array}$ & $\begin{array}{c}\text { Group B } \\
\text { Insulin } \\
(\text { No. }=100)\end{array}$ & $\begin{array}{c}p \text { - } \\
\text { value }\end{array}$ \\
\hline $\begin{array}{l}\text { FBS at time of } \\
\text { diagnosis: }\end{array}$ & & & \\
$\quad$ Mean \pm SD & $110.1 \pm 6.39$ & $108.72 \pm 6.6$ & 0.141 \\
$\quad$ Range & $96-124$ & $96-125$ & \\
$\begin{array}{l}\text { FBS after } 3 \text { weeks } \\
\text { of treatment: }\end{array}$ & & & \\
$\quad$ Mean \pm SD & $92.58 \pm 3.36$ & $94.9 \pm 2.49$ & $<0.001$ \\
$\quad$ Range & $85-99$ & $87-99$ & \\
$\begin{array}{l}\text { FBS at last week } \\
\text { of delivery: }\end{array}$ & & & \\
$\quad$ Mean \pm SD & $89.1 \pm 3.84$ & $93.6 \pm 2.24$ & $<0.001$ \\
$\quad$ Range & $80-96$ & $88-98$ & \\
\hline
\end{tabular}

There was no significant difference between the metformin group and the Insulin group in regard to the $2 \mathrm{~h} \mathrm{PP}$ in the beginning of the study. However, after the treatment, the $2 \mathrm{~h}$ PP levels were significantly lower in both metformin and insulin groups. Additionally, the postprandial glucose levels were numerically lower with metformin treatment but did not reach statistical significance (Table 3).

Table (3):Comparison between the two groups according to 2 hour postprandial ( $2 \mathrm{hPP})$.

\begin{tabular}{llll}
\hline \multicolumn{1}{c}{ Groups } & $\begin{array}{c}\text { Group A } \\
\text { Metformin } \\
(\text { No.=94) }\end{array}$ & $\begin{array}{c}\text { Group B } \\
\text { Insulin } \\
\text { Variables }\end{array}$ & $\begin{array}{c}p \text { - } \\
\text { value }\end{array}$ \\
\hline $\begin{array}{l}\text { 2hPP at time of } \\
\text { diagnosis: }\end{array}$ & & & \\
$\quad \begin{array}{l}\text { Mean } \pm \mathrm{SD} \\
\text { Range }\end{array}$ & $176.24 \pm 7.53$ & $175.27 \pm 11.39$ & 0.483 \\
$\begin{array}{l}\text { 2hPP after 3 weeks } \\
\text { of treatment: }\end{array}$ & $158-197$ & $161-199$ & \\
$\quad \begin{array}{l}\text { Mean } \pm \mathrm{SD} \\
\text { Range }\end{array}$ & $112.4 \pm 6.8$ & $113.77 \pm 7.66$ & 0.189 \\
$\begin{array}{l}\text { 2hPP at last week } \\
\text { of delivery: }\end{array}$ & $100-119$ & $102-120$ & \\
$\quad \begin{array}{l}\text { Mean } \pm \mathrm{SD} \\
\text { Range }\end{array}$ & $103.5 \pm 7.95$ & $105.28 \pm 7.22$ & 0.105 \\
\hline
\end{tabular}

There was no significant difference between two groups regarding $\mathrm{HbA} 1 \mathrm{c}$ in the beginning of the study. However, the metformin group had significantly lower $\mathrm{HbA1c}$ levels at 37 week of gestation (Table 4).
Table (4): Comparison between group A and group B according to glycated hemoglobin.

\begin{tabular}{|c|c|c|c|}
\hline Groups & $\begin{array}{l}\text { Group A } \\
\text { Metformin } \\
\text { (No.=94) }\end{array}$ & $\begin{array}{l}\text { Group B } \\
\text { Insulin } \\
(\text { No.=100) }\end{array}$ & $\begin{array}{c}p- \\
\text { value }\end{array}$ \\
\hline \multicolumn{4}{|l|}{$\begin{array}{l}\text { HbAl c at time of } \\
\text { diagnosis: }\end{array}$} \\
\hline Mean $\pm \mathrm{SD}$ & $6.08 \pm 0.41$ & $6.02 \pm 0.61$ & 0.42 \\
\hline Range & $5.8-6.4$ & $5.6-6.4$ & \\
\hline $\begin{array}{l}\text { HbAl c during } \\
\text { last week }\end{array}$ & & & \\
\hline $\begin{array}{l}\text { of delivery: } \\
\text { Mean } \pm \mathrm{SD}\end{array}$ & $5.13 \pm 0.34$ & $5.43 \pm 0.37$ & $<0.001$ \\
\hline Range & $4.6-5.8$ & $4.4-5.9$ & \\
\hline
\end{tabular}

There was a significantly less maternal weight gain with the metformin group compared to the insulin group. Additionally, there was significant difference between the two groups in respect to the mean gestational age of delivery but it is clinically small difference. Furthermore, there was no significant difference between the metformin group and the Insulin group in regard to the rate of Csections. Nevertheless, Cesarean section deliveries due to macrosomia were significantly more in insulin treated patients than in metformin treated patients with a ratio of $(2: 1)$ (Table 5).

Table (5): Comparison between group A and group B according tomaternal obstetric outcome.

\begin{tabular}{|c|c|c|c|}
\hline $\begin{array}{l}\text { Groups } \\
\text { Variables }\end{array}$ & $\begin{array}{l}\text { Group A } \\
\text { Metformin } \\
\text { (No.=94) }\end{array}$ & $\begin{array}{c}\text { Group B } \\
\text { Insulin } \\
(\text { No.=100) }\end{array}$ & $\begin{array}{c}p- \\
\text { value }\end{array}$ \\
\hline \multicolumn{4}{|l|}{$\begin{array}{l}\text { 1- Gestational week } \\
\text { of delivery: }\end{array}$} \\
\hline Mean \pm SD & $37.76 \pm 0.86$ & $38.07 \pm 1.28$ & 0.048 \\
\hline Range & $35.5-39$ & $36-40$ & \\
\hline \multicolumn{4}{|l|}{$\begin{array}{l}\text { 2- Maternal weight } \\
\text { gain }(\mathrm{kg}) \text { : }\end{array}$} \\
\hline Mean \pm SD & $6.98 \pm 0.68$ & $9.37 \pm 1.60$ & $<0.001$ \\
\hline Range & $6-8$ & $7-12$ & \\
\hline \multicolumn{4}{|l|}{ 3- Mode of delivery: } \\
\hline $\begin{array}{l}\text { Normalvaginal } \\
\text { delivery }\end{array}$ & $22(23.4 \%)$ & $22(22.0 \%)$ & 0.818 \\
\hline Cesarean section & $72(76.6 \%)$ & $78(78.0 \%)$ & \\
\hline \multicolumn{4}{|l|}{ Indication for $C / S$} \\
\hline \multicolumn{4}{|l|}{ no. $(\%):$} \\
\hline $\begin{array}{l}\text { - Pre-eclampsia }+ \\
\quad \text { unfavourable cervix }\end{array}$ & $5(6.9 \%)$ & $4(5.1 \%)$ & 0.639 \\
\hline - Previous uterine surgeries & $22(30.6 \%)$ & $21(26.9 \%)$ & 0.622 \\
\hline - Macrosomia (big baby) & $12(16.7 \%)$ & $24(30.8 \%)$ & 0.027 \\
\hline - Primi Breech presentation & $4(5.6 \%)$ & $3(3.8 \%)$ & 0.619 \\
\hline - Foetal jeopardy & $9(12.5 \%)$ & $10(12.8 \%)$ & 0.956 \\
\hline $\begin{array}{l}\text { - Cephalo-pelvic } \\
\text { disproportion }\end{array}$ & $7(9.7 \%)$ & $5(6.4 \%)$ & 0.455 \\
\hline
\end{tabular}


Neonatal birth weight was significantly lower in the metformin group than that of the insulin group. In addition, neonatal hypoglycemia and NICU admission were statistically significantly lower in the metformin group in comparison to the insulin group. However, there was no significant difference between the two group regarding neonatal respiratory distress and 5min-APGAR score (Table 6).

Table (6): Comparison between group A and group B according to fetal outcome.

\begin{tabular}{llll}
\hline \multicolumn{1}{c}{ Groups } & $\begin{array}{c}\text { Group A } \\
\text { Metformin } \\
(\text { No.=94) }\end{array}$ & $\begin{array}{c}\text { Group B } \\
\text { Insulin } \\
(\text { No.=100) }\end{array}$ & $\begin{array}{c}p \text { - } \\
\text { value }\end{array}$ \\
Variables & & & \\
\hline Neonatal hypoglycemia: & & & \\
$\quad$ No & $82(87.2 \%)$ & $76(76.0 \%)$ & 0.044 \\
$\quad$ Yes & $12(12.8 \%)$ & $24(24.0 \%)$ & \\
Respiratory distress: & & & \\
$\quad$ No & $90(95.7 \%)$ & $92(92.0 \%)$ & 0.28 \\
$\quad$ Yes & $4(4.3 \%)$ & $8(8.0 \%)$ & \\
NICU admission: & & & \\
$\quad$ No & $81(86.2 \%)$ & $71(71.0 \%)$ & 0.01 \\
$\quad$ Yes & $13(13.8 \%)$ & $29(29.0 \%)$ & \\
Apgar score: & & & \\
Mean \pm SD & $7.9 \pm 0.8$ & $8.1 \pm 0.7$ & 0.066 \\
Range & $7-10$ & $7-10$ & \\
Birth weight $($ gm): & & & \\
$\quad$ Mean \pm SD & $3410.15 \pm$ & $3649.55 \pm$ & $<0.001$ \\
$\quad$ Range & 480.08 & 468.87 & \\
\hline
\end{tabular}

\section{Discussion}

Uncontrolled gestational diabetes is closely linked with an increased incidence of adverse outcomes for both mother and fetus. When women fail to achieve euglycemia with lifestyle interventions, the optimal pharmacologic agent for GDM treatment is questionable [4]. Historically, insulin has been the standard GDM treatment. Newer data, including Metformin in Gestational Diabetes (MiG) trial, suggest that metformin may be an acceptable alternative to insulin for GDM treatment [9]. A key target of our study was to assess the efficacy of metformin in controlling gestational diabetes compared to insulin.

Concerning patients' characteristics in both groups, there were no significant differences between the two groups regarding maternal age, primigravida, GA at time of diagnosis, $\mathrm{BMI}$ at the time of diagnosis, and $\mathrm{HbAlc}$ at time of diagnosis. This was in agreement with the study of Niromanesh et al., [10] and Ghomian et al., [11]. However, the study of Spaulonci et al., [12] reported that a median number of 3 pregnancies (with insulin) versus 2 pregnancies (with metformin). This difference might be due to the various ethnic groups and the slightly older maternal age.

With respect to glycemic control, no significant difference in pre-treatment glucose levels was observed between the two groups. However, after giving the drugs, the glucose levels were significantly lower in both metformin and insulin groups.

Fasting glucose was significantly lower in the metformin group after 3 weeks of treatment. In addition, the average fasting blood glucose level continued throughout gestation to be significantly lower in metformin treated group. This was in agreement with the studies of Gui et al., [13] who reported thatthe fasting blood sugar levels were significantly lower in the metformin only group than in the supplemental insulin group. However, the study of Niromanesh et al., [10] found that the fasting blood glucose was numerically lower with metformin treatment versus insulin treatmentbut did not reach statistical significance.

Regarding the 2 hours postprandial glucose levels, we found that there was an insignificant statistical difference between the two groups at last week of delivery. This was in line with the study of Ghomian et al., [11] who reported that 2 hours postprandial throughout treatment until delivery did not show any statistically significant difference. Additionally, a meta-analysis by Guo et al., [14] reported that there was no significant statistical difference between the insulin and metformin groups in terms of 2-hours plasma glucose (2hPG).

As for evaluation of glycosylated hemoglobin at 37 th week, the findings indicated lower mean of HbA1c among metformin group, with a statistically significant difference. Results from the study conducted by Mesdaghinia et al., [15] displayed significantly lower levels of $\mathrm{HbA} 1 \mathrm{c}$ in the metformin group. This agrees with the long-standing knowledge that Metformin acts mainly by suppressing hepatic glucose production, leading to a reduction in fasting plasma glucose levels and $\mathrm{HbA} 1 \mathrm{c}$ [16]

Concerning the time of delivery, Kitwitee et al., [17] and $\mathrm{Li}$ et al., [18] found that gestational ages at delivery were lower with metformin treatment. This was in agreement with the current study as we found that the mean gestational age of delivery in the metformin-treated group was less than in the insulin-treated group. This was statistically significant but clinically small difference. 
In the current study, it was clear that cesarean section (CS) deliveries due to macrosomia were significantly more in insulin-treated patients $(30.8 \%)$ than in metformin-treated patients $(16.7 \%)$ with a ratio of 2: 1 . Nevertheless, the rate of CS were found to be $76.6 \%$ and $78.0 \%$ for metformin and insulin groups respectively which was insignificant. This was in agreement with Gui et al., [13] and Tertti et al., [19] who showed that the rates of cesarean section were similar in both groups. However, Ijäs et al., [20] found that there were more Cesarean deliveries in the metformin group than in the insulin group which might be a result of an increased incidence of intrapartum CS for prolonged labor or presumed fetal compromise.

Comparison between the two studied groups regarding weight gain during pregnancy showed that the insulin group have weight gain values statistically higher than metformin group. This was an unsurprising finding, Niromanesh et al., [10] found that the insulin group had a statistically significantly higher weight gain than the metformin group. Also Ainuddin et al., [21] demonstrated that there was less maternal weight gain with metformin than insulin.

In the present study, the average birth weight of the new borns were significantly lower in the metformin treated group. There were 24 cases with birth weight more than or equal to $4 \mathrm{~kg}$, (macrosomia) in the insulin group compared to 12 cases with that weight in the metformin group. This was an agreement with a meta-analysis of 32 RCTs by Liang et al., [5] who revealed that metformin had lower birth weight and lowest incidence of macrosomia and large for gestational age (LGA) compared to glyburide and insulin. Also, Ainuddin et al., [21] demonstrated a lower birth weight in metformin-treated pregnancies.

Concerning Apgar score (at 5min) in our study, the majority of the neonates were born with an Apgar score > 7, and there was no significant difference between the two groups. This was in consensus with various other studies such as Tertti et al., [19] and Guo et al., [14] who found no significant differences in regard to the Apgar score.

Neonatal hypoglycemia was found in $12.7 \%$ and $24.0 \%$ of Metformin and insulin groups respectively with a statistical significant difference. The results from the current study were consistent with those obtained by Spaulonci et al., [12] who found a lower frequency of neonatal hypoglycemia with metformin with statistical significance. Additionally, in a study done by Ijäs et al., [20], the frequency of neonatal hypoglycemia was slightly but not significantly higher in the insulin group.

Insulin group have more risk of neonatal respiratory distress than metformin group but there were no statistical significant differences. This is consistent with the study of Feng and Yang [22] who noted that there was no difference in neonataloutcome including respiratory distress. However, Mesdaghinia et al., [15] reported higher incidence of respiratory distress and NICU admission in the insulin group.

Neonatal intensive care unit (NICU) admission had occurredin $13.8 \%$ and $29.0 \%$ of Metformin and insulin group respectively. There was statistical significant difference between the two groups. This was an agreement with Kitwitee et al., [17] and also Li et al., [18] who noted a lower rate of NICU admission with metformin.

The findings of our study provided muchneeded information on real-world effectiveness of metformin compared with insulin. No substantial differences in effectiveness between metformin and insulin as treatment for GDM on the basis of a wide array of clinically relevant maternal and child outcomes.

\section{Conclusion:}

Metformin has an efficacy as that of insulin in glycemic control of GDM, and has additional advantages regarding reduction of maternal weight gain as well as neonatal birth weight, and also lowering poor neonatal outcomes, namelyneonatal hypoglycemia and NICU admission.

\section{References}

1- CHEN L., MAGLIANO D.J. and ZIMMET P.Z.: The worldwide epidemiology of type 2 diabetes mellituspresent and future perspectives. Nature Reviews Endocrinology, 8 (4): 228-236, 2012.

2- American Diabetes Association: Diagnosis and classification of diabetes mellitus. Diabetes Care, 37 (Supplement 1): S81-S90, 2014.

3- MARCHETTI D., CARROZZINO D., FRATICELLI F., FULCHERI M. and VITACOLONNA E.: Quality of life in women with gestational diabetes mellitus: A systematic review. Journal of diabetes research, article ID 7058082: 1-12, 2017.

4- MCINTYRE H.D., CATALANO P., ZHANG C., DESOYE G., MATHIESEN E.R. and DAMM P.: Gestational diabetes mellitus. Nature Reviews Disease Primers, 5 (1): 1-19, 2019.

5- LIANG H.L., MA S.J., XIAO Y.N. and TAN H.Z.: Comparative efficacy and safety of oral antidiabetic drugs and insulin in treating gestational diabetes mellitus: An updated 
PRISMA-compliant network meta-analysis. Medicine, 96 (38): e7939-e7939, 2017.

6- CASSINA M., DONA M., DI GIANANTONIO E., LITTA P. and CLEMENTI M.: First-trimester exposure to metformin and risk of birth defects: A systematic review and meta-analysis. Human Reproduction Update, 20 (5): 65669, 2014.

7- ANGUEIRA AR., LUDVIK AE, REDDY TE, WICKSTEED B, LOWE WL and LAYDEN BT: New insights into gestational glucose metabolism: Lessons learned from 21 st century approaches. Diabetes, 64 (2): 327-34, 2015.

8- American Diabetes Association: Management of diabetes in pregnancy: Standards of Medical Care in Diabetes2018. Diabetes Care, 41 (Supplement 1): S137-S143, 2018 .

9- BALSELLS M., GARCÍA-PATTERSON A., SOLÀ I., ROQUÉ M., GICH I. and CORCOY R.: Glibenclamide, metformin, and insulin for the treatment of gestational diabetes: A systematic review and meta-analysis. BMJ, 350: h102-h102, 2015.

10- NIROMANESH S., ALAVI A., SHARBAF F.R, AMJADI N., MOOSAVI S. and AKBARI S.: Metformin compared with insulin in the management of gestational diabetes mellitus: A randomized clinical trial. Diabetes Research and Clinical Practice, 98 (3): 422-429, 2012.

11- GHOMIAN N., VAHED S.H., FIROUZ S., YAGHOUBI M.A., MOHEBBI M. and SAHEBKAR A.: The efficacy of metformin compared with insulin in regulating blood glucose levels during gestational diabetes mellitus: A randomized clinical trial. Journal of Cellular Physiology, 234 (4): 4695-701, 2019.

12- SPAULONCI C.P., BERNARDES L.S., TRINDADE T.C., ZUGAIB M. and FRANCISCO R.P.: Randomized trial of metformin vs insulin in the management of gestational diabetes. American Journal of Obstetrics and Gynecology, 209 (1): 34-e1, 2013.

13- GUI J., LIU Q. and FENG L.: Metformin vs insulin in the management of gestational diabetes: A meta-analysis. PloS ONE, 8 (5): e64585-e64585, 2013.

14- GUO L., MA J., TANG J., HU D., ZHANG W. and ZHAO X.: Comparative efficacy and safety of metformin, glyburide, and insulin in treating gestational diabetes mellitus:
A meta-analysis. Journal of Diabetes Research, article ID 9804708: 1-29, 2019.

15- MESDAGHINIA E., SAMIMI M., HOMAEI Z., SABERI F., MOOSAVI S.G. and YARIBAKHT M.: Comparison of newborn outcomes in women with gestational diabetes mellitus treated with metformin or insulin: A randomised blinded trial. International Journal of Preventive Medicine, 4 (3): 327-333, 2013.

16- GEORGE P. and MCCRIMMON R.J.: Potential role of non-insulin adjunct therapy in type 1 diabetes. Diabetic Medicine, 30 (2): 179-188, 2013.

17- KITWITEE P., LIMWATTANANON S., LIMWATTANANON C., WALEEKACHONLERT O., RATANACHOTPANICH T., PHIMPHILAI M. and PONGCHAIYAKUL C.: Metformin for the treatment of gestational diabetes: An updated meta-analysis. Diabetes Research and Clinical Practice, 109 (3): 521-532, 2015.

18- LI G., ZHAO S., CUI S., LI L., XU Y. and LI Y.: Effect comparison of metformin with insulin treatment for gestational diabetes: A meta-analysis based on RCTs. Archives of Gynecology and Obstetrics, 292 (1): 111 120,2015

19- TERTTI K., EKBLAD U., KOSKINEN P., VAHLBERG T. and RÖNNEMAA T.: Metformin vs. insulin in gestational diabetes. A randomized study characterizing metformin patients needing additional insulin. Diabetes, Obesity and Metabolism, 15 (3): 246-251, 2013.

20- IJÄS H., VÄÄRÄSMÄKI M., MORIN-PAPUNEN L., KERAVUO R., EBELING T., SAARELA T. and RAUDASKOSKI T.: Metformin should be considered in the treatment of gestational diabetes: A prospective randomised study. BJOG: An International Journal of Obstetrics and Gynaecology, 118 (7): 880-885, 2011.

21- AINUDDIN J., KARIM N., HASAN A.A. and NAQVI S.A.: Metformin versus insulin treatment in gestational diabetes in pregnancy in a developing country. A randomized control trial. Diabetes Research and Clinical Practice, 107 (2): 290-299, 2015.

22- FENG Y.E. and YANG H.: Metformin-a potentially effective drug for gestational diabetes mellitus: A systematic review and meta-analysis. The Journal of Maternal-Fetal \& Neonatal Medicine, 30 (15): 1874-1881, 2017. 


\title{
مقارنة بين الميتفورمين والإنسولين فى سكر الحمل
}

\author{
خلفية البحث: يُعتبر الميتفومين تدخلاً منطقياً بفرض أن استخدامه المرضى الحوامل فعال وآمن. \\ الهدف من البحث: تقييم فعالية الميتفومين فى السيطرة على سكر الحمل بالمقارنة مع الإنسولين.
}

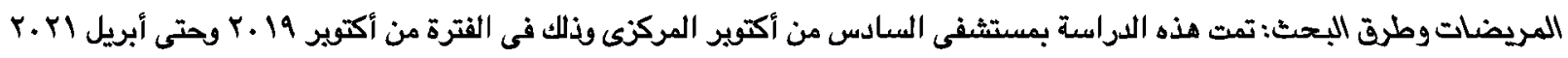

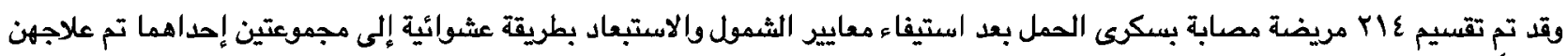

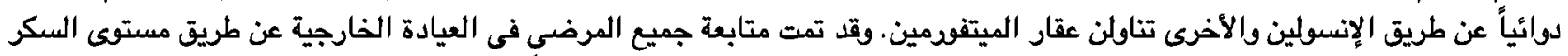

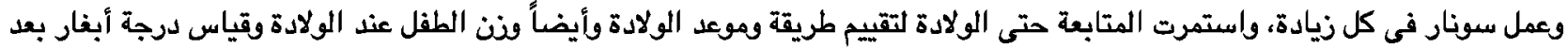

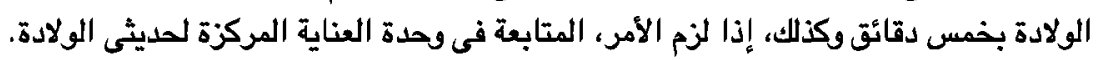

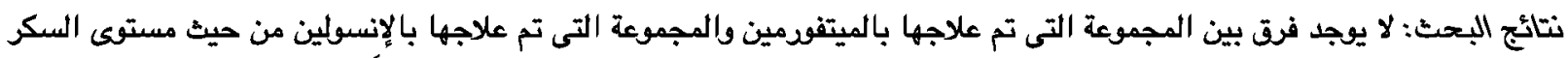

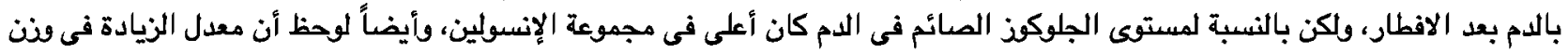

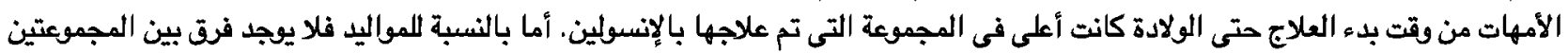

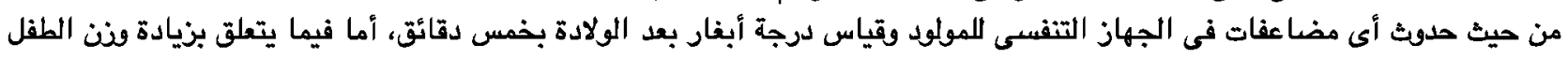

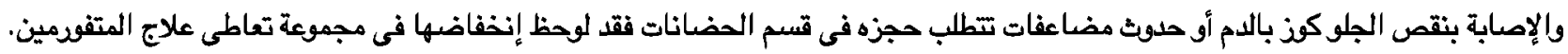
الإستتاج: كان الميتفورمين فعّالا مثل الإنسولين فى السيطرة على سكر الحمل. 